\title{
Efeito da lâmina de irrigação na conservação pós-colheita de melão Pele de Sapo
}

\author{
José Francismar de Medeiros; Edna MM Aroucha; Indalécio Dutra; Sérgio WP Chaves; Marcelo S de \\ Souza
}

UFERSA, C. Postal 137, 59625-900 Mossoró-RN; jfmedeir@ufersa.edu.br; aroucha@ufersa.edu.br; idutra@ufersa.edu.br; swchaves@, ufersa.edu.br; sobreira@gmail.com

\section{RESUMO}

Sabe-se que há influência das condições de cultivo na qualidade e conservação pós-colheita dos frutos, sendo escassos na literatura os trabalhos que relacionem o uso de lâmina de irrigação com a qualidade e conservação pós-colheita do melão. Assim, objetivou-se avaliar o efeito da lâmina de irrigação na conservação pós-colheita de melão Pele de Sapo. Para isto, conduziu-se um experimento em uma área localizada no município de Mossoró (RN), de setembro a dezembro de 2004. O ensaio consistiu do plantio do meloeiro utilizando três lâminas de irrigação $\mathrm{L}_{1}=281 \mathrm{~mm}, \mathrm{~L}_{2}=349$ e $\mathrm{L}_{3}=423 \mathrm{~mm}$, com solo adubado seguindo a exigência da cultura. Os frutos foram colhidos na maturidade fisiológica (60 dias após o transplantio). Em seguida foram transportados para o Laboratório de Pós-colheita da UFERSA, onde se procederam à seleção e lavagem. Uma amostragem dos frutos foi avaliada previamente e os demais foram identificados, embalados e armazenados em câmara refrigerada com temperatura regulada a $10 \pm 1^{\circ} \mathrm{C}$ e $85 \pm 2 \%$ UR por 35 dias. O delineamento experimental foi inteiramente casualizado, em esquema fatorial $3 \times 2$ constituindo-se respectivamente três lâminas de irrigação $\left(\mathrm{L}_{1}, \mathrm{~L}_{2}, \mathrm{e} \mathrm{L}_{3}\right)$ e dois períodos de armazenamento dos frutos ( 0 e 35 dias), com seis repetições. Verificou-se interação significativa entre lâminas de irrigação e tempo de conservação para vitamina $\mathrm{C}$. Houve acréscimo do $\mathrm{pH}$ e diminuição da vitamina $\mathrm{C}$ e firmeza de polpa com o incremento da lâmina de irrigação. A firmeza da polpa, acidez e sólidos solúveis dos frutos diminuíram após o período de armazenamento.

Palavras-chave: Cucumis melo, fisiologia pós-colheita, armazenamento, vitamina $\mathrm{C},{ }^{\circ} \mathrm{Brix}$.

\author{
ABSTRACT \\ Irrigation effect in the postharvest conservation of Piel de \\ Sapo melon
}

The occurrence of effects of cultivation conditions on the postharvest quality and conservation of fruits is already known, but the studies are scarce, in the literature, which relate the use of irrigation with postharvest quality and conservation of melon. Thus, the objective was to evaluate the irrigation effect in the postharvest conservation of Piel de Sapo melon. An experiment was carried out in Mossoró, Rio Grande do Norte state, Brazil, from September to December 2004 in which three irrigation levels tested: $\mathrm{L}_{1}=281 \mathrm{~mm}$, $\mathrm{L}_{2}=349 \mathrm{~mm}$ and $\mathrm{L}_{3}=423 \mathrm{~mm}$, the soil being fertilized according to the crop needs. The fruits were harvested at physiological maturity (60 days after transplantation). After the harvest, the fruits were transported to the laboratory of the Universidade Federal Rural do Semiárido, where the fruits were washed and selected. A sampe was evaluated previously and the other fruits were identified and placed in cardboard boxes. They were stored in a cooler with temperature at $10 \pm 1^{\circ} \mathrm{C}$ and $85 \pm 2 \% \mathrm{RH}$ where they remained for 35 days. The experimental design was completely randomized in a $3 \times 2$ factorial, representing respectively three irrigation levels $\left(\mathrm{L}_{1}, \mathrm{~L}_{2}\right.$ and $\left.\mathrm{L}_{3}\right)$ and two fruits storage periods ( 0 and 35 days), with five replications. Significant differences were detected between the irrigation levels and storage time to vitamin $\mathrm{C}$. There occurred an increase on the $\mathrm{pH}$ value and a decrease on vitamin $\mathrm{C}$ content and on fruits pulp firmness with higher irrigation levels. The pulp firmness, acidity and soluble solids of fruits decreased after storage time.

Keywords: Cucumis melo, postharvest physiology, storage, vitamin C, ${ }^{\circ}$ Brix.

(Recebido para publicação em 9 de setembro de 2011; aceito em 30 de julho de 2012) (Received on September 9, 2011; accepted on July 30, 2012)

\begin{abstract}
A região Nordeste do Brasil, por apresentar condições ótimas de cultivo, clima semi-árido e alta luminosidade, é responsável pela maior quantidade de melão (Cucumis melo) produzido no país. Atualmente é uma das culturas mais importantes do Rio Grande do Norte com 32\% da produção nordestina, seguido de Ceará e Bahia com $54 \%$ e $7 \%$, respectivamente (IBGE, 2010).
\end{abstract}

A área explorada com irrigação no Nordeste, segundo o Censo
Agropecuário de 2006, é de 985.000 ha, mas com potencial de se expandir de forma sustentável para 1.304.000 ha (MI, 2012). No Rio Grande do Norte, a região do Pólo Agrícola Mossoró/Assu, devido às condições edafoclimáticas e à presença de águas superficiais represadas e subterrâneas, tem se destacado pelo cultivo de fruteiras tropicais e olerícolas irrigadas, inclusive o melão, produzindo tanto para o mercado interno quanto externo.

As condições ambientais que favorecem o cultivo do meloeiro estão relacionadas aos fatores climáticos temperatura, umidade relativa e luminosidade. A combinação de alta temperatura, de 25 a $35^{\circ} \mathrm{C}$, com alta luminosidade, na faixa de 2.000 a 3.000 horas/ano, e baixa umidade relativa, entre 65 e $75 \%$, favorece ao estabelecimento do meloeiro e ao aumento de produtividade com maior número de frutos de qualidade comercial (aumenta o conteúdo de açúcares, melhora o aroma, o sabor e a 
consistência dos frutos) (Costa, 2012).

A importância nutricional é outro fator que favorece o cultivo do meloeiro. Normalmente, na adubação orgânica do melão, recomenda-se $20 \mathrm{~m}^{3} \mathrm{ha}^{-1}$ de esterco de curral bem curtido ou 2.000 $\mathrm{kg} \mathrm{ha}^{-1}$ de torta de mamona, também bem curtida. Como adubação mineral, recomenda-se $40 \mathrm{~kg} \mathrm{ha}^{-1}$ de $\mathrm{N}$ e doses de 40 a $160 \mathrm{~kg} \mathrm{ha}^{-1}$ de $\mathrm{P}_{2} \mathrm{O}_{5}$ e $\mathrm{K}_{2} \mathrm{O}$, conforme a análise do solo, a serem aplicados em fundação, antes do plantio. Para adubação de cobertura, o período de aplicação de nitrogênio via água de irrigação para o meloeiro é de até 42 dias após a germinação, enquanto, que o potássio vai até os 55 dias após a germinação com as doses de $100 \mathrm{~kg} \mathrm{ha}^{-1}$ de $\mathrm{N}$ e $90 \mathrm{~kg} \mathrm{ha}^{-1}$ de $\mathrm{K}_{2} \mathrm{O}$ (Costa, 2012).

A agricultura irrigada depende da quantidade e da qualidade da água. A utilização eficiente da água está se tornando cada vez mais importante devido à escassez de recursos hídricos na região e ao elevado custo da energia, o que torna cada vez mais necessário o uso de metodologias apropriadas ao manejo racional do uso da água.

Para Medeiros et al. (2003), a maioria das culturas exploradas na região semiárida é classificada como sensível a moderadamente sensível à salinidade. Dessa forma é importante estabelecer o manejo adequado das plantas, solo e sistemas de irrigação. Em qualquer condição de estresse a planta responde a esse efeito sobre a produtividade e principalmente sobre a qualidade dos frutos.

A utilização de lâmina reduzida de irrigação tem sido uma forma de manejo da água de irrigação em regiões semiáridas que visam otimizar o uso da água, mas pode implicar muitas vezes em menor produtividade de frutos (Medeiros et al., 2007; Saldanha, 2004), mas frutos com maior teor de sólidos solúveis (Andrade Júnior et al., 2001). Enquanto, as lâminas altas, embora possam aumentar a produtividade, conduzem ao aparecimento de frutos rachados (Filgueiras et al., 2000) e frutos com menor teor de sólidos solúveis (Medeiros et al., 2000). Para a exportação do melão Pele de Sapo, a aparência externa juntamente com o peso dos frutos e teor de sólidos solúveis são características importantes utilizadas pelas empresas agrícolas.

Os melões produzidos comercialmente pertencem a dois grupos botânicos: Cucumis melo inodorus e $C$. melo cantaloupensis, que correspondem, respectivamente, aos melões inodoros e aos melões aromáticos. O melão Pele de Sapo (inodoro) é um fruto de tamanho grande, com a polpa verde, consistência firme, é resistente às condições de transporte e tem maior vida útil póscolheita (Menezes et al., 2000).

A exportação de melão do grupo inodorus ao contrário do grupo cantaloupensis, requer apenas o uso de frio. Atualmente são transportados em contêineres refrigerados, uma técnica eficiente e bastante difundida na cadeia de comercialização de frutas e hortaliças. Para o melão Pele de Sapo, o armazenamento dos frutos a temperatura de $10 \pm 1^{\circ} \mathrm{C}$ mantém o fruto sob bom estado de conservação até cerca de 42 dias, semelhante ao melão amarelo (Tomaz et al., 2009).

Entretanto, as características dos frutos ao longo do período de armazenamento podem ser alteradas em níveis diferentes, dependendo das condições de cultivo que as plantas foram conduzidas (Danner et al., 2009, Hojo et al., 2009).

Levando em consideração a importância da irrigação na produção do melão, este trabalho teve por objetivo avaliar o efeito de lâminas de irrigação na conservação pós-colheita de melão Pele de Sapo.

\section{MATERIAL E MÉTODOS}

O experimento foi conduzido de setembro a dezembro de 2004 em área localizada no município de Mossoró (4'54'16"S, 37²2'00' W, altitude 30 $\mathrm{m})$. O clima da região, de acordo com a classificação de Koeppen, é do tipo BSwh', ou seja , quente e seco; com precipitação pluviométrica bastante irregular, média anual de 673,9 mm; temperatura de $27^{\circ} \mathrm{C}$ e umidade relativa do ar média de 68,9\% (Carmo Filho \& Oliveira, 1989).

O solo da área foi classificado como Argissolo Vermelho-Amarelo Eutrófico latossólico (EMBRAPA, 1999) com as características: $\mathrm{Ca}=2,75, \mathrm{Mg}=1,35, \mathrm{~K}=$ $0,47, \mathrm{Na}=0,041, \mathrm{Al}=0,0\left(\mathrm{em} \mathrm{cmol} \mathrm{dm}^{-3}\right)$ e $\mathrm{P}=1,92 \mathrm{mg} \mathrm{dm}^{-3}, \mathrm{pH}=7,6$. A água de irrigação foi proveniente de poço que explora o aqüífero calcário Jandaíra, que apresenta as seguintes características: $\mathrm{CE}=2,7 \mathrm{dS} \mathrm{m}^{-1}, \mathrm{pH}=7,0, \mathrm{Ca}=9,0, \mathrm{Mg}=$ $4,7, \mathrm{~K}=0,12, \mathrm{Na}=14,8, \mathrm{Cl}=16,8, \mathrm{HCO}=$ 7,0 e $\mathrm{CO}_{3}=0,4\left(\mathrm{em} \mathrm{mmol} \mathrm{dm}^{-3}\right)$.

O trabalho foi dividido em duas etapas: campo e laboratório. No campo, foram instalados três experimentos numa mesma área e conduzidos ao mesmo tempo, utilizando-se em cada experimento uma lâmina de irrigação diferente. $\mathrm{O}$ delineamento experimental utilizado foi em blocos casualizados num arranjo fatorial $3 \times 3+2$ em quatro repetições. Os tratamentos do fatorial consistiram da combinação de três doses de nitrogênio e três doses de potássio, acrescentando dois tratamentos adicionais, via fertirrigação. Na etapa de laboratório, foi selecionado o tratamento que corresponde às doses de $\mathrm{N}$ e $\mathrm{K}$ adotadas pelos produtores da região, para cada experimento de lâmina de irrigação. Na segunda etapa, o delineamento experimental utilizado foi inteiramente casualizado, em esquema fatorial $3 \times 2$ constituindose respectivamente de três lâminas de irrigação $\left(\mathrm{L}_{1}, \mathrm{~L}_{2}\right.$ e $\left.\mathrm{L}_{3}\right)$ e dois períodos de armazenamento dos frutos (0 e 35 dias), com seis repetições.

A adubação de plantio foi realizada tomando-se como base as adubações usualmente utilizadas pelos produtores de melão da região sendo aplicados os seguintes produtos: fosfato monoamônio (MAP, 10-52-00), correspondendo a 39 $\mathrm{kg} \mathrm{ha}^{-1}$ de $\mathrm{N}$ e $203 \mathrm{~kg} \mathrm{ha}^{-1}$ de $\mathrm{P}_{2} \mathrm{O}_{5}$, e do composto natural BioAtivo ${ }^{\circledR}$ (0-12-0), equivalente a $93,75 \mathrm{~kg} \mathrm{ha}^{-1}$ de $\mathrm{P}_{2} \mathrm{O}_{5}$, totalizando $296,75 \mathrm{~kg} \mathrm{ha}^{-1}$ de $\mathrm{P}_{2} \mathrm{O}_{5}$. O complemento nutricional do fósforo foi realizado via fertirrigação utilizando-se ácido fosfórico, no total de $148,6 \mathrm{~kg} \mathrm{ha}^{-1}$ de $\mathrm{P}_{2} \mathrm{O}_{5}$. As fontes de $\mathrm{N}$ e $\mathrm{K}_{2} \mathrm{O}$ utilizadas em cobertura via fertirrigação foram uréia, ácido nítrico, cloreto de potássio e sulfato de potássio, correspondendo a $140 \mathrm{~kg} \mathrm{ha}^{-1}$ de $\mathrm{N}$ e $260 \mathrm{~kg} \mathrm{ha}^{-1}$ de $\mathrm{K}_{2} \mathrm{O}$.

A cultivar de melão do grupo inodorus utilizada foi 'Sancho', do tipo Pele de Sapo. A semeadura foi 
realizada em bandejas de 128 células e aos 11 dias após a semeadura (DAS), as mudas foram transplantadas para o campo. O espaçamento utilizado para plantio em campo foi de $1,85 \times 0,4 \mathrm{~m}$, com uma muda por cova, resultando numa população de 13.514 plantas ha-1.

O sistema de irrigação foi o localizado por gotejamento, utilizando um gotejador por planta. Estas plantas foram cultivadas sob o regime de três lâminas de irrigação, onde foram definidas em função da necessidade total de irrigação (NTI), sendo $\mathrm{L}_{1}=0,7$. NTI, $\mathrm{L}_{2=}=0,9$.NTI e $\mathrm{L}_{3}=1,1 . \mathrm{NTI},(281$, 349 e $423 \mathrm{~mm}$, respectivamente). A NTI foi calculada diariamente a partir da estimativa da evapotranspiração da cultura (ETc) utilizando a metodologia do coeficiente de cultura dual, segundo Allen et al. (2006) e os dados climáticos referentes ao período de condução do experimento, obtidos na estação meteorológica da UFERSA. Os valores médios mensais das variáveis climáticas foram: temperatura média de $28,6^{\circ} \mathrm{C}$ $( \pm 0,1)$; umidade relativa média do ar de $61,8 \%( \pm 2,9)$; número de horas de insolação de $10,2 \mathrm{~h} \mathrm{dia}^{-1}( \pm 0,8)$; precipitação pluviométrica de $0 \mathrm{~mm}$; velocidade do vento a $10 \mathrm{~m}$ de $6,1 \mathrm{~m} \mathrm{~s}^{-1}$ $( \pm 0,4)$ e evapotranspiração de referência de 7,3 $\mathrm{mm} \mathrm{dia}^{-1}( \pm 0,4)$. Além disso, adotou-se uma eficiência de aplicação de água de $91 \%$, com base na avaliação do sistema de irrigação.

Os melões foram colhidos aos 60 dias após o transplantio (DAT), quando atingiram a maturidade fisiológica, tamanho, peso e coloração da casca, característicos da cultivar. Em seguida foram transportados para o Laboratório de Pós-Colheita da UFERSA, onde foram caracterizados previamente por meio de amostragem de 12 frutos de cada tratamento. Após a limpeza, pesagem e identificação os frutos foram armazenados por um período de 35 dias em câmara de refrigeração regulada a $10 \pm 1^{\circ} \mathrm{C}$ e $85 \pm 2 \%$ UR, com o intuito de verificar o efeito das lâminas de irrigação no período de comercialização final.

Foram avaliadas as características dos frutos: Firmeza da polpa (Firm) [divisão longitudinal do fruto em duas partes e, em cada uma delas, realização de duas leituras na polpa, em locais opostos na região equatorial, com penetrômetro marca McCormick, modelo FT 327 analógico (ponteira de 8 mm de diâmetro); resultados expressos em Newton (N)]; Acidez titulável (AT) (titulação de uma alíquota do suco com solução de $\mathrm{NaOH}$ a $0,1 \mathrm{~N}$, na presença do indicador fenolftaleína a $1 \%$; resultados expressos em $\%$ de ácido cítrico); Potencial hidrogeniônico $(\mathrm{pH})$ (determinado no suco em duplicata, utilizando-se potenciômetro digital da marca Marte, modelo MB-10); Sólidos solúveis (SS) (realizado utilizando refratômetro digital modelo PR-100 Palette (Attago Co. Ltd., Japan), com correção automática de temperatura e leitura na faixa de 0 a $32{ }^{\circ}$ Brix); Açúcares solúveis totais (AST) (obtidos segundo metodologia de Yemn; Willis (1954); Vitamina C (determinada pelo método titulométrico com DFI e a relação SS/AT, foi efetuada após divisão do teor de SS pela porcentagem de AT).

Os dados foram submetidos à análise da variância, teste de Tukey a 5\% de probabilidade e análise do desdobramento. As analises foram realizadas utilizando o software SISVAR.

\section{RESULTADOS E DISCUSSÃO}

Observou-se efeito de lâminas de irrigação para as características firmeza de polpa, $\mathrm{pH}$ e vitamina $\mathrm{C}$. Verificou-se efeito de período de armazenamento para quase todas as características estudadas, as únicas exceções foram vitamina $\mathrm{C}$ e açúcares solúveis totais. Houve interação significativa entre os fatores lâminas de irrigação e período de armazenamento somente para a característica vitamina $\mathrm{C}$, indicando comportamento diferenciado dos dois níveis do fator lâmina de irrigação nos diferentes períodos de armazenamento. A presença da interação evidencia a dependência entre os dois fatores e exige um estudo mais aprofundado pelo desdobramento dos níveis de um fator em função dos níveis de um segundo fator. Por outro lado, a ausência da interação permite que os dois fatores sejam estudados independentemente.

Na Tabela 1, verificou-se decréscimo da vitamina $\mathrm{C}$ no final do armazenamento (35 dias) apenas para o tratamento com menor lâmina de irrigação (Tabela 1). Mesmo com maior média de vitamina $\mathrm{C}$ no tempo 0 dias, verificou-se nos frutos submetidos à lâmina de irrigação de $281 \mathrm{~mm}$ maior decréscimo por unidade de tempo quando comparado aos frutos cultivados com as lâminas de irrigação de 349 e $423 \mathrm{~mm}$. Porém, esse fato não resultou em maior redução de vitamina $\mathrm{C}$ ao final do tempo de armazenamento. Por outro lado, apesar dos frutos oriundos das lâminas de irrigação de 348 e $423 \mathrm{~mm}$, apresentarem no tempo 0 menor teor de vitamina $\mathrm{C}$, aos 35 dias de armazenamento os teores de vitamina $\mathrm{C}$ de todos os tratamentos foram semelhantes. O aumento da vitamina $\mathrm{C}$ verificado, aos 35 dias, nos frutos provenientes da maior lâmina de irrigação (423 mm) está relacionado, possivelmente, a um efeito diluidor da maior lâmina, no tempo 0 , com uma possível perda de massa durante o período de armazenamento dos frutos.

Em estudos realizados com melão

Tabela 1. Valores médios para o desdobramento da lâmina de irrigação dentro dos períodos de armazenamento, e vice-versa, para a característica vitamina $\mathrm{C}$ (mean values for the unfolding of irrigation within the storage periods, and vice versa, for the characteristic vitamin $\mathrm{C}$ ). Mossoró, UFERSA, 2005.

\begin{tabular}{lccc}
\hline \multirow{2}{*}{ Armazenamento (dias) } & \multicolumn{3}{c}{ Lâmina de irrigação (mm) } \\
\cline { 2 - 4 } & $\mathbf{2 8 1}$ & $\mathbf{3 4 9}$ & $\mathbf{4 2 3}$ \\
\hline 0 & $121,12 \mathrm{aA}^{*}$ & $12,91 \mathrm{aB}$ & $9,46 \mathrm{bB}$ \\
35 & $13,20 \mathrm{bA}$ & $13,49 \mathrm{aA}$ & $15,55 \mathrm{aA}$ \\
\hline
\end{tabular}

*Valores seguidos por mesmas letras, minúsculas e maiúsculas, nas colunas e linhas, respectivamente, não diferem estatisticamente pelo teste de Tukey a $5 \%$ de probabilidade; ${ }^{1} \mathrm{mg}$ ácido ascórbico $100 \mathrm{~mL}^{-1}$ ( values followed by the same uppercase and lowercase letters, in the rows and columns, respectively, did not differ from each other by the test Tukey $(p<0.05)$; ${ }^{1} \mathrm{mg}$ ascorbic acid $\left.100 \mathrm{~mL}^{-1}\right)$. 
Tabela 2. Valores médios de firmeza de polpa (FP), pH, sólidos solúveis (SS), acidez titulável (AT), açúcares solúveis totais (AST) e relação sólidos solúveis/acidez titulável (SS/AT) do melão Pele de Sapo cultivado em diferentes lâminas de irrigação em função do tempo de armazenamento (mean values of the pulp firmness (FP), $\mathrm{pH}$, soluble solids (SS), titratable acidity (AT), total soluble sugars (AST) and soluble solids/acidity (SS/AT) of Piel de Sapo melon, cultivated in different irrigation levels depending on the storage period). Mossoró, UFERSA, 2005.

\begin{tabular}{lcccccc}
\hline $\begin{array}{l}\text { Lâmina de irrigação } \\
\text { (mm) }\end{array}$ & $\mathbf{F P}^{1}$ & $\mathbf{p H}$ & $\mathbf{S S}^{2}$ & $\mathbf{A T}^{\mathbf{3}}$ & $\mathbf{A S T}^{\mathbf{4}}$ & $\mathbf{S S} / \mathbf{A T}$ \\
\hline 281 & $15,26 \mathrm{a}$ & $6,58 \mathrm{~b}$ & $11,75 \mathrm{a}$ & $0,12 \mathrm{a}$ & $10,58 \mathrm{a}$ & $108,39 \mathrm{a}$ \\
349 & $13,33 \mathrm{~b}$ & $6,87 \mathrm{ab}$ & $11,46 \mathrm{a}$ & $0,11 \mathrm{a}$ & $10,75 \mathrm{a}$ & $113,32 \mathrm{a}$ \\
423 & $14,81 \mathrm{a}$ & $6,92 \mathrm{a}$ & $11,23 \mathrm{a}$ & $0,11 \mathrm{a}$ & $10,66 \mathrm{a}$ & $107,12 \mathrm{a}$ \\
\hline $\begin{array}{l}\text { Armazenamento } \\
\text { (dias) }\end{array}$ & & & & & & \\
\hline 0 & $20,91 \mathrm{a}^{*}$ & $6,35 \mathrm{~b}$ & $11,77 \mathrm{a}$ & $0,14 \mathrm{a}$ & $10,66 \mathrm{a}$ & $83,03 \mathrm{~b}$ \\
35 & $8,03 \mathrm{~b}$ & $7,23 \mathrm{a}$ & $11,19 \mathrm{~b}$ & $0,08 \mathrm{~b}$ & $10,67 \mathrm{a}$ & $136,19 \mathrm{a}$ \\
\hline
\end{tabular}

*Médias seguidas de mesma letra nas colunas não diferem significativamente entre si pelo teste de Tukey a $5 \%$ de probabilidade; ${ }^{1}$ Newton; ${ }^{20}$ Brix; ${ }^{30} \%$ de ácido cítrico; ${ }^{40} \%$ ( ${ }^{*}$ means followed by the same letter in the column did not differ from each other by Tukey test ( $\mathrm{p}<0.05$ ); ${ }^{1}$ Newton; ${ }^{2 \circ}$ Brix; ${ }^{30} \%$ of citric acid; ${ }^{40} \%$ ).

rendilhado (Cucumis melo) híbridos 'Maxim', 'Bônus n²', 'Shinju 200', 'Fantasy' e 'Louis', em função do sistema de cultivo (substrato e solo), Vargas et al. (2008) observaram que o conteúdo de vitamina $\mathrm{C}$ médio foi de $15,77 \mathrm{mg}$ de vitamina $\mathrm{C} / 100 \mathrm{~mL}$, no cultivo em solo.

Não obstante a redução da vitamina $\mathrm{C}$ com o armazenamento dos frutos, aos 35 dias, nenhuma lâmina de irrigação resultou em frutos com concentração de vitamina $C$ insignificante. Da mesma forma, Souza et al. (2008) verificaram em melão Charentais, diminuição no teor de vitamina $\mathrm{C}$ no final do armazenamento.

$\mathrm{O}$ teor de vitamina $\mathrm{C}$ é um atributo de qualidade interessante, devido a sua função antioxidante; apesar disto o melão não chega a ser fonte expressiva dessa vitamina. Aroucha et al. (2007) detectaram os maiores teores de vitamina $\mathrm{C}$ em melão caipira $(48,40$ $\mathrm{mg}$ de vitamina $\mathrm{C} / 100 \mathrm{~mL}$ ) e os menores valores para os melões do tipo Amarelo e Pele de Sapo (19 e 23 mg de vitamina $\mathrm{C} / 100 \mathrm{~mL}$ ).

Perdas de nutrientes podem ocorrer com o armazenamento, especialmente de vitamina $\mathrm{C}$, devido aos processos fisiológicos e bioquímicos (Chitarra \& Chitarra, 2005). É importante ressaltar que a vitamina $\mathrm{C}$ é bastante instável, e pode ser transformada enzimaticamente por reações oxidativas, na sua forma reversível (ácido hidroascórbico) e/ou irreversível (ácido 2,3 dicetogulônico), (Watada, 1987), podendo causar a diminuição da vitamina $\mathrm{C}$.

O tratamento com lâmina de irrigação 281 e $423 \mathrm{~mm}$ manteve a firmeza de polpa superior $(14,81-15,26$ N) em comparação com aqueles em lâmina de 349 mm (13,33 N) (Tabela 2). Esse resultado não era esperado uma vez que o incremento da lâmina de irrigação para melão, conforme Follegati et al. (2004), diminui a firmeza de polpa com o incremento da irrigação.

A firmeza de polpa do melão Pele de Sapo varia conforme o hibrido, em média situa-se em torno de 28,22 e $27 \mathrm{~N}$ (híbridos 'Sancho', 'PS 07' e 'Tendency 27', respectivamente), (Nunes et al., 2008), e de $32 \mathrm{~N}$ (híbrido 'Imara'), (Filgueiras et al., 2000), no momento da colheita. É um atributo de qualidade importante, em razão dos frutos com maior firmeza serem mais resistentes às injúrias mecânicas durante o transporte e comercialização. Frutos colhidos com maior firmeza da polpa têm, geralmente, maior conservação e vida útil pós-colheita.

A firmeza da polpa reduziu com o tempo de armazenamento independente da lâmina de irrigação utilizada (Tabela 2), sendo que a redução aos 35 dias foi $38,41 \%$. Há evidências que a atividade da pectinametilesterase promova o amaciamento gradual do melão durante o armazenamento (Menezes et al., 2000). Resultados semelhantes foram verificados em melão Cantaloupe (Gomes Junior et al., 2001), Amarelo (Paiva et al., 2008; Tomaz et al., 2009) com decréscimo linear na firmeza dos frutos durante o período de armazenamento. Os melões classificados como inodorus têm uma menor redução da firmeza da polpa ao longo do tempo de armazenamento quando comparado aos frutos da variedade cantaloupensis (Aroucha et al., 2009).

Verificou-se que o $\mathrm{pH}$ dos frutos aumentou com o incremento da lâmina de irrigação (Tabela 3). Esse resultado era de certa forma esperado uma vez que a lâmina de irrigação exerce um fator diluidor nos componentes dos frutos e o pH é medida de mol de $\mathrm{H}^{+} / \mathrm{L}$.

Houve aumento do $\mathrm{pH}$ em função do tempo de armazenamento dos frutos independente da lâmina de irrigação adotada (Tabela 2). E paralelamente, também, observou-se redução da acidez titulável. Essa tendência de decréscimo da acidez titulável e acréscimo do $\mathrm{pH}$ era esperada uma vez que após a colheita, a concentração de ácidos orgânicos tende a declinar na maioria dos frutos, devido à larga utilização desses compostos como substrato respiratório e como esqueleto de carbono para a síntese de novos compostos, enfatiza Kays (1991). Da mesma forma, Tomaz et al. (2009) verificaram decréscimo na acidez titulável e aumento no $\mathrm{pH}$ de melão Amarelo ao longo do período de armazenamento do fruto.

$\mathrm{Na}$ maioria dos frutos a acidez titulável representa um dos principais componentes do flavor, pois sua aceitação depende do balanço entre ácidos e açúcares (Chitarra \& Chitarra, 2005). No melão Pele de Sapo, a variação nos níveis de acidez tem pouco significado em função da baixa concentração $(0,11 \%)$, com isso a intervenção da acidez no sabor não é muito representativa.

Não foi observada alteração significativa nos teores de sólidos solúveis quanto às lâminas de irrigação estudadas (Tabela 2). Resultados semelhantes foram observados por 
Negreiros et al. (2005). Diferente destes resultados, Vasquez et al. (2005) registraram diminuição dos sólidos solúveis em melão com a aplicação de reduzida lâmina de água no solo.

Observou-se efeito de tempo de armazenamento sobre o teor de sólidos solúveis (Tabela 2). Esse ocorreu porque parte dos sólidos solúveis são compostos por açúcares solúveis e no melão este representa $65-85 \%$ dos sólidos solúveis (Chitarra \& Chitarra, 2005). É de certa forma esperado, levando em consideração que açúcares são consumidos no processo respiratório (Kays, 1991) para manutenção do metabolismo normal da célula.

O teor de sólidos solúveis é um parâmetro de qualidade importante na classificação de melão pelo USDA (United States Departament of Agriculture). Apesar de estabelecido previamente em contratos, o melão Pele de Sapo é colhido pelo menos com $12 \%$ de sólidos solúveis (Suslow, 2009). No presente trabalho, os melões apresentaram teores de sólidos solúveis abaixo do mínimo aceitável para a comercialização no mercado externo. A princípio poderiam ser rejeitados para o mercado externo, contudo, ressaltase que a metodologia de determinação de sólidos solúveis na fazenda (sem homogeneização da polpa) para melão inodorus aumenta o índice em $2,3^{\circ}$ Brix quando comparada á medida realizada em laboratório (com homogeneização da polpa) (Mendes, 2009). Sendo assim, o melão após 35 dias de armazenado estaria apto ainda para a comercialização externa.

Não foi observada alteração significativa nos teores de açúcares solúveis totais conforme as lâminas de irrigação estudadas e/ou do tempo de armazenamento (Tabela 2). Os teores de AST em média variaram em torno de $10,66 \%$, resultados acima dos obtidos por Tomaz et al. (2009) em diferentes híbridos de melão tipo Amarelo (7,37$8,71 \%)$. Zhang \& Li (2005) enfatizaram que o melão possui em torno de $97 \%$ dos sólidos solúveis constituídos por açúcares solúveis, de forma que a sacarose compreende cerca de $50 \%$ desse total.

A proporção SS/AT, indicativo do índice de maturidade e sabor do fruto, não foi significativa com as lâminas de irrigação (Tabela 2). Após o período de armazenamento aumentou a relação SS/ $\mathrm{AT}$, em virtude da diminuição dos ácidos orgânicos, utilizados possivelmente no processo fisiológico do fruto (Kays, 1991). Resultados semelhantes foram verificados durante o armazenamento de melão tipo Charentais por Souza et al. (2008) e em função de diferentes sistemas de cultivo por Vargas et al. (2008).

Verificou-se diminuição do teor de vitamina $\mathrm{C}$ com o incremento da lâmina de irrigação. Entretanto, após 35 dias de armazenamento, os frutos ainda apresentaram teores de vitamina C satisfatórios para a comercialização.

A firmeza da polpa não diminuiu com a maior lâmina de irrigação utilizada $(423 \mathrm{~mm})$. No entanto, constatou-se diminuição após o período de armazenamento.

Houve acréscimo do $\mathrm{pH}$ dos frutos com o incremento das lâminas de irrigação, enquanto, a acidez e teor de sólidos solúveis diminuíram após o período de armazenamento.

De maneira geral, constata-se que o acréscimo da lâmina de irrigação não influenciou de forma substancial o aspecto qualitativo dos frutos. Essa constatação é um indicativo de que melhor lâmina de irrigação pode ser definida com base somente na produtividade, pois verificouse aumento de $55,6 \%$ na produção comercial de frutos em função das lâminas de irrigação.

\section{REFERÊNCIAS}

ALLEN RG; PEREIRA LS; RAES D; SMITH M. 2006. Evapotranspiración del cultivo: guías para la determinación de los requerimientos de agua de los cultivos. Roma: FAO. 298p. (FAO: Irrigation and Drainage Paper, 56).

ANDRADE JÚNIOR AS; FRIZZONE JA; BASTOS EA; CARDOSO MJ; RODRIGUES BHN. 2001. Estratégias ótimas de irrigação para a cultura da melancia. Horticultura Brasileira 19: 301-305.

AROUCHA EMM; MORAES FA; NUNES GHS; TOMAZ HVQ; SOUSA AED; BEZERRA NETO F. 2007. Caracterização física e química de melão durante o seu desenvolvimento. Revista Brasileira de Fruticultura 29: 296301.
AROUCHA EMM; NUNES GHS; SOUSAAED; FERNANDES PLO; SOUZA MS. 2009. Qualidade e potencial pós-colheita de híbridos de melão. Revista Ceres 56: 181-185.

CARMO FILHO F; OLIVEIRA OF. 1989. Mossoró um município do semi-árido nordestino: características climáticas e aspectos florísticos. Mossoró: 62p. (Coleção Mossoroense, 672. Série B).

COSTA ND. 2012, 24 de fevereiro. O cultivo do melão. Disponível em: http:// http:// www.hortibrasil.org.br/jnw/images/stories/ Melao/m.69.pdf/

CHITARRA MIF, CHITARRA AB. 2005. Póscolheita de frutos e hortaliças: fisiologia e manuseio. 2. Ed. Lavras: Editora UFLA, 785p.

DANNER MA; CITADIN I; SASSO SAZ; ZARTH NA; MAZARRO SM. 2009. Fontes de cálcio aplicadas no solo e sua relação com a qualidade de uva 'Venus'. Revista Brasileira de Fruticultura 31: 881-889.

EMBRAPA. Sistema brasileiro de classificação de solos. 1999. Rio de Janeiro: CNPS. 412p.

FILGUEIRAS HAC; MENEZES JB; ALVES RE; COSTA FV; PEREIRA LSE; GOMES JUNIOR J. 2000. Colheita e manuseio póscolheita. In: ALVES RE. (org). Melão Póscolheita. Fortaleza: Embrapa Agroindústria Tropical, p. 23-43.

FOLLEGATI MV; VASQUEZ MAN; DIAS NS; SOUZA VF. 2004. Qualidade física do melão fertirrigado com diferentes dosagens de K e lâminas de irrigação, em gotejamentos superficial e subsuperficial. Revista Irriga 9: $52-61$.

GOMES JUNIOR J; MENEZES JB; NUNES GHS; COSTAFB; SOUZAPA. 2001. Qualidade póscolheita de melão tipo Cantaloupe, colhido em dois estádios de maturação. Horticultura Brasileira 19: 356-360.

HOJO RH; SÃO JOSÉ AR; HOJO ETD; ALVES JFT; REBOUÇAS TNH; DIAS NO. 2009. Qualidade de manga 'Tommy Atkins' póscolheita com uso de cloreto de cálcio na pré-colheita. Revista Brasileira Fruticultura 31: 62-70.

IBGE - INSTITUTO BRASILEIRO DE GEOGRÁFIA E ESTATÍSTICA. 2010, 17 de março. Produção agrícola estadual. Disponível em: http://www.ibge.gov.br/ servidor_arquivos_est/

KAYS JS. 1991. Postharvest physiology of perishable plant products. New York: Van Nostrand Reinhold, 532p.

MEDEIROS JF; LISBOA RA; OLIVEIRA M; SILVA JUNIOR MJS; ALVES LP. 2003. Caracterização das águas subterrâneas usadas para irrigação na área produtora de melão da Chapada do Apodi. Revista Brasileira de Engenharia Agrícola e Ambiental 7: 469-472.

MEDEIROS JF; NASCIMENTO IB; COSTA MC; SCALOPPI EJ. 2000. Produção de melão sob diferentes lâminas de água com dois níveis de salinidade. Horticultura Brasileira 18: 612614, Suplemento.

MEDEIROS JF; SANTOS SCL; CÂMARA MJT; NEGREIROS MZ. 2007. Produção de melão Cantaloupe influenciado por coberturas do solo, agrotêxtil e lâminas de irrigação. 
Horticultura Brasileira 25: 538-543.

MENDES FIB. 2009. Comparação de metodologias de determinação de sólidos solúveis e avaliação de firmeza em Melão Amarelo (AF642) e Cantaloupe (Americano). Mossoró: UFERSA. 40p. (Monografia).

MENEZES JB; FILGUEIRAS HAC; ALVES RE; MAIA CE; ANDRADE CE; ANDRADE GG; ALMEIDA JHS; VIANAFMP. Características do melão para exportação. In: ALVES RE. (org). Melão: pós-colheita. Brasília, DF: Embrapa Comunicação para Transferência de Tecnologia; Fortaleza: Embrapa Agroindústria Tropical, 2000. (Frutas do Brasil, 10).

MI-MINISTÉRIO DA INTEGRAÇÃO NACIONAL. 2012, 24 de fevereiro. Funcionamento da secretaria nacional de irrigação. Disponível em: http://www. agricultura.gov.br/arq_editor/file/camaras tematicas/Agricultura_sustentavel_e irrigacao/14RO/Apres_Senir_resumo.pdf/

NEGREIROS MZ; COSTA FA; MEDEIROS JF; LEITÃO MMVBR; BEZERRA NETO F; SOBRINHO JE. 2005. Rendimento e qualidade do melão sob lâminas de irrigação e cobertura do solo com filmes de polietileno de diferentes cores. Horticultura Brasileira 23: 773-779.
NUNES GHS; PEREIRA EWL; SALES JÚNIOR R; BEZERRA NETO F; OLIVEIRA KC; MESQUITA LX. 2008. Produtividade e qualidade de frutos de melão Pele de Sapo em duas densidades de plantio. Horticultura Brasileira 26: 236-239.

PAIVA WO; MARQUES GV; MESQUITA JBR; DANTAS RS; FREITAS FWA. 2008. Qualidade e conservação de frutos de melão Amarelo em dois pontos de colheita. Revista Ciência Agronômica 39: 70-76.

SALDANHA TRFC. 2004. Produção e qualidade de melão cantaloupe cultivado sob condições de diferentes tipos de cobertura e lâminas de irrigação. Mossoró: UFERSA. 105p. (Tese mestrado).

SOUZA PA; FINGER FL; ALVES RE; PUIATTI M; CECON PR; MENEZES JB. 2008. Conservação pós-colheita de melão Charentais tratado com 1-MCP e armazenamento sob refrigeração e atmosfera modificada. Horticultura Brasileira 26: 464-470.

SUSLOW TV; CANTWELL M; MITCHELL J. Produce Facts: Cantaloupe. Department of Vegetable Crops, University of California, Davis, 2009.

TOMAZ HVQ; AROUCHA EMM; NUNES GHS;
NETO FB; TOMAZ HVQ; QUEIROZ RF. 2009. Qualidade pós-colheita de diferentes híbridos de melão-amarelo armazenados sob refrigeração. Revista Brasileira de Fruticultura 31: 987-994.

VARGAS PF; CASTOLDI R; CHARLO HCO; BRAZ LT. 2008. Qualidade de melão rendilhado (Cucumis melo L.) em função do sistema de cultivo. Ciência Agrotecnologia 32: $137-142$.

VASQUEZ MAN; FOLEGATTI MV; DIAS NS; SOUZA VF. 2005. Qualidade pós-colheita de frutos de meloeiro fertirrigado com diferentes doses de potássio e lâminas de irrigação. Revista Brasileira de Engenharia Agrícola e Ambiental 9: 199-204.

YEMN EW; WILLIS AJ. 1954. The estimation of carbohydrate in plant extracts by anthrone. The Biochemical Journal 57: 508-514.

ZHANG MF; LI ZL. 2005. A comparison of sugar accumulating patterns and relative compositions in developing fruits of two oriental melon varieties as determined by HPLC. Food Chemistry 90: 785-790.

WATADAAE. Vitamins. 1987. In: WEICHMANN J. Postharvest physiology of vegetables. NewYork: M. Dekker, p.455-467. 